\title{
Morbidity of the lower genital tract during pregnancy
}

\author{
VALERIE C. STANLEY, J. B. JONES, ROSALINDE HURLEY, J. E. B. FOULKES, \\ AND J. DE LOUVOIS
}

From Queen Charlotte's Hospital for Women and the Institute of Obstetrics and Gynaecology, University of London, Goldhawk Road, London W6 $3 X G$

SYNOPSIS The lower genital tract of 280 pregnant women was studied in detail, and symptoms relevant to its morbidity were elicited and recorded. The study was contemporaneous with a study of microbial flora in the genital tract of these women (de Louvois et al, 1975).

Complaint was made most frequently of discharge $(42 \%)$, irritation $(15 \%)$, or both $(11 \%)$. Apart from these symptoms, $14 \%$ admitted a past history of vulvovaginitis, emphasizing the importance of this condition in obstetric and gynaecological practice. The notorious discrepancyes between the complaint, and the objective demonstration of discharge, was confirmed, but a sig-O nificant difference in observations, varying with the clinical observer $(P<0.001)$, was also demon- $\frac{\mathbb{P}}{3}$ strated. This illustrates the necessity of even more accurate grading of signs when clinicopathological correlations are to be attempted. Only $30 \%$ of women had no evidence of vulvovaginitis or cervicitis. Morbidity did not relate to age, gestation or parity, but there was a significant correg tion between clinical acumen, as evidenced by a request for a microbiological report with a view $f_{0}$ treatment, and morbidity $(\mathrm{P}<0.001)$, between past vulvovaginitis and present morbidity $(\mathrm{P}<0.0$ 电), and between cervicitis and the presence of pus cells in the smear $(\mathrm{P}<0.001)$.

The results indicate that microbiological investigations should be requested when there is pasto history of vulvovaginitis, and that lesions of the cervix, if not already noted, should be suspectedo if pus cells are demonstrable in stained smears.

Many workers have sought to incriminate microbes other than Trichomonas vaginalis and Candida albicans as causes of superficial infection of the female lower genital tract. With the exception of infections associated with herpesvirus hominis type 2 (Hutfield, 1970) most attempts have foundered for lack of adequate liaison between clinical and scientific observers, and the clinicopathological inferences drawn have often proved to be false or, at best, extremely doubtful.

We have attempted to correlate observations made on the microbial flora of the lower genital tract in pregnancy with clinical observations relating to disordered anatomy or physiology of the tract. In this paper, we give an account of the signs and symptoms encountered, their frequency, their relationship to age, parity, and length of gestation, to past history of vulvovaginitis, to clinical suspicion of morbidity, and to the presence of pus cells in stained smears of the vaginal secretion.

Received for publication 25 March 1975.

\section{Methods}

POPULATION INVESTIGATED

Two hundred and eighty women booking consecutively at the antenatal clinics of Queen Charlotte's Hospital for Women over a two-month period were studied prospectively. Those in whom examination via speculum was contraindicated were excluded? but otherwise the patients were unselected. The patients were interviewed and examined by one of. two obstetricians. Appropriate clinical data wers recorded and specimens were taken for microbiological examination; details of the mode of collection, of the pathological investigations and of the methods used in our laboratories are given is this issue (de Louvois et al, 1975).

\section{CLINICAL EXAMINATION}

The vaginal walls and cervix were exposed with aO bivalve Cusco's speculum lubricated with KY jello (Johnson \& Johnson), and anatomical and physio? 
logical observations were recorded on a standard questionnaire. Vaginal discharge apparent to the clinician was noted, distinction being made between slight discharge (not soiling the underwear) and heavy discharge (soiling the underwear). Vulvitis, vaginitis, cervicitis, and cervical erosion were defined according to the criteria of Jeffcoate (1967) and were graded according to severity. Laboratory reports were not issued unless requested by the clinician upon suspicion of vulvovaginitis requiring treatment.

ANALYSIS OF DATA

Standard clinical questionnaires and laboratory data sheets were used. The questionnaire was completed on a yes/no basis, and this information, with the laboratory findings, was transferred to punch cards for computer analysis.

\section{Results}

In table I the population investigated is analysed according to age, parity, and gestation time; relatively few of the patients fell within obstetric high risk groups: $6 \%$ were over 34 years of age, $2 \%$ were grand multipara, and $5 \%$ booked within the third trimester. The majority of patients were European $(80 \%)$, were married $(89 \%)$, and were aged between 18 and 34 years $(89 \%)$. There were approximately equal numbers of primigravidae and multigravidae, and a high proportion (55\%) booked between the 13th and 25th week of gestation.

Table II summarizes the major clinical findings relevant to possible microbial disease of the lower genital tract. Eighteen had conditions other than those specified: three had retained IUCD, and two had vulval warts; otherwise the diseases ranged from systemic to local conditions. None of the patients was diabetic or receiving steroid therapy; five were anaemic and 16 had an asymptomatic urinary infection. None of the $\mathbf{4 0}$ patients who had a past history of vulvovaginitis was receiving therapy. Although eight women had received antimicrobial

\begin{tabular}{lrl}
\hline Clinical Findings & No. & $\%$ of Population \\
\hline Complaint of discharge & 119 & 42 \\
Complaint of irritation & 41 & 15 \\
Complaint of discharge + irritation & 31 & 11 \\
Past history of vulvovaginitis & 40 & 14 \\
Diabetes & 0 & 0 \\
Piles & 10 & 4 \\
Steroid therapy & 0 & 0 \\
Antimicrobial therapy & 8 & 3 \\
Other condition & 18 & 6 \\
Significant bacteriuria & 16 & 6 \\
Haemoglobin $<11$ g/dl & 5 & 2 \\
\hline
\end{tabular}

Table II Clinical findings in 280 unselected pregnant women

therapy within the previous two weeks, none was being treated at the time of examination. One patient had had previous treatment for syphilis, but all were seronegative at the time of booking. Complaints of irritation and discharge were frequent. Of the 41 patients complaining of irritation, 20 complained of vulval irritation: six had perivaginal irritation only, 13 complained of vulval and perivaginal irritation, one of vulval with perivaginal and perianal irritation, and one of vulval and perianal irritation.

Although the complaint of vaginal discharge may be dependent on the patient's fastidiousness, on personal hygiene, or on her idea of 'normal', table

\begin{tabular}{lcc}
\hline & $\begin{array}{l}\text { Patients complaining } \\
\text { of Discharge }\end{array}$ & $\begin{array}{l}\text { Patients not } \\
\text { complaining of } \\
\text { Discharge }\end{array}$ \\
\hline Total & $119(83 \%)$ & $\begin{array}{c}161 \\
52(32 \%)\end{array}$ \\
$\begin{array}{l}\text { Discharge observed } \\
\text { No discharge observed }\end{array}$ & $99(17 \%)$ & $109(68 \%)$ \\
Clinician I & 80 & 67 \\
Total & $74(92 \%)$ & $14(21 \%)$ \\
Discharge observed & $6(8 \%)$ & $53(79 \%)$ \\
No discharge observed & & 94 \\
Clinician II & $39(64 \%)$ & $38(40 \%)$ \\
Total & $25(64 \%)$ & $56(60 \%)$ \\
Discharge observed & $14(36 \%)$ & \\
No discharge observed & &
\end{tabular}

Table III Vaginal discharge in 280 unselected pregnant women

\begin{tabular}{|c|c|c|c|c|c|c|c|c|}
\hline \multicolumn{3}{|l|}{ Age } & \multicolumn{3}{|l|}{ Parity } & \multicolumn{3}{|c|}{ Gestation } \\
\hline Years & No. & $\%$ of Pop. & Pregnancies & No. & $\%$ of Pop. & Weeks & No. & $\%$ of Pop. \\
\hline $\begin{array}{l}<18 \\
18-34 \\
>34\end{array}$ & $\begin{array}{r}13 \\
251 \\
16\end{array}$ & $\begin{array}{r}5 \\
89 \\
6\end{array}$ & $\begin{array}{l}1 \\
2-4 \\
>4\end{array}$ & $\begin{array}{r}143 \\
132 \\
5\end{array}$ & $\begin{array}{r}51 \\
47 \\
2\end{array}$ & $\begin{array}{l}13 \\
13-25 \\
25\end{array}$ & $\begin{array}{r}112 \\
153 \\
15\end{array}$ & $\begin{array}{r}40 \\
55 \\
5\end{array}$ \\
\hline
\end{tabular}

Table I Population investigated-280 unselected pregnant women

$\begin{array}{ll}\text { European } & =236(80.4 \%) \\ \text { Negro } & =19 \\ \text { Indian/Pakistani } & =10 \\ \text { Others } & =15 \\ \text { Married } & =250\end{array}$


III shows that objective assessment of discharge seems also to be subject to variation, and that the complaint, and the objective assessment of discharge, do not coincide. Discharge was observed in 99 of 119 women who complained of it $(83 \%)$ and was not observed in $20(17 \%)$. Conversely, of 161 not complaining, discharge was observed in 52 (32\%). Each obstetrician examined about the same number of patients (147 and 133 respectively) and statistical analysis showed a significant difference in their observations. Sixty-two percent of women complaining had discharge discernible to clinician I, compared with only $21 \%$ who had discharge discernible to clinician II $(\mathrm{P}<0.001): 5 \%$ had no discharge according to clinician I and $12 \%$ had none according to clinician II $(\mathrm{P}<0.01)$. Of those not so complaining, clinician II found more women $(24 \%)$ to have discernible discharge than clinician I $(9 \%)$.

The population was divided into three categories according to clinical assessment of the general state of health or disease of the lower genital tract. Those designated as 'healthy' had no discernible anatomical or physiological abnormality. Patients with a 'slightly morbid lower genital tract' included women with mild signs which were: (a) slight discharge only; (b) reddened cervix only; (c) both these signs; and $(d)$ a miscellaneous group, including those with cervical erosion, slight discharge with cervical $\stackrel{0}{5}$ erosion, reddened cervix and erosion, reddened $\stackrel{0}{-}$ vagina or vulva, reddened vagina and slight dis- $\overrightarrow{\vec{A}}$ charge, Nabothian follicles, or any of the preceding $\stackrel{\text { ? }}{\rightarrow}$ with Nabothian follicles. The patients described as having a 'severely morbid lower genital tract' had $\frac{\bar{c}}{\bar{c}}$ a single severe sign or multiple signs of morbidity. $\vec{\nabla}$ Eighty-three women $(30 \%)$ had a completely $\varrho$ healthy lower genital tract; $39 \%$ had mild signs of $\%$ morbidity and $32 \%$ had severe or multiple signs of $\vec{\circ}$ lower genital tract morbidity (table IV).

Only three of 41 women $(7 \%)$ complaining of $\vec{\omega}$ irritation had a healthy tract, while $27(66 \%)$ had? severe lower genital tract morbidity. Discharge was? common and was observed in $151(54 \%)$ of the women. Cervicitis and/or cervical erosion wasio observed in $130(47 \%)$. The number of women $N$ regarded as having a healthy lower genital tract or ${ }^{\circ}$ slight morbidity did not differ significantly with the 을 observer, but severe or multiple signs of morbidity $\overrightarrow{-}$ were more commonly observed by clinician I $(22 \%)$ than by clinician II (10\%). The difference is statistic- $\frac{\mathrm{O}}{\mathbb{D}}$ ally significant $(P<0.001)$. A reddened cervix with 3 or without slight discharge was more frequently. described by clinician II.

The clinical findings in 89 patients with severe $\vec{\oplus}$ lower genital tract morbidity are summarized $\mathrm{g} n$ ? table V. Severe discharge alone or any discharge đ્đ

\begin{tabular}{|c|c|c|c|}
\hline Lower Genital Tract & No. of Patients & Clinician I & Clinician II \\
\hline Healthy & $83(30 \%)$ & $36(13 \%)$ & $47(16 \%)$ \\
\hline $\begin{array}{l}\text { Slightly morbid } \\
\text { a Slight discharge only } \\
\text { b Red cervix only } \\
\text { c a }+ \text { b } \\
\text { d Other mild signs }\end{array}$ & $\begin{array}{l}108(39 \%) \\
40 \\
19 \\
31 \\
18\end{array}$ & $\begin{array}{l}50(18 \%) \\
21 \\
4 \\
10 \\
15\end{array}$ & $\begin{array}{l}58(21 \%) \\
19 \\
15 \\
21 \\
3\end{array}$ \\
\hline Severely morbid & $89(32 \%)$ & $61(22 \%)$ & $28(10 \%)$ \\
\hline Total & 280 & $147(52 \%)$ & $133(48 \%)$ \\
\hline
\end{tabular}

Table IV Lower genital tract morbidity

\begin{tabular}{|c|c|c|c|}
\hline Clinical Finding & Total & Clinician I & Clinician II \\
\hline $\begin{array}{l}\text { No. of patients examined } \\
\text { No. of patients with severe morbidity } \\
\text { Vulvitis (total) } \\
\text { Severe vulvitis } \\
\text { Vaginitis (total) } \\
\text { Severe vaginitis } \\
\text { Cervicitis (total) } \\
\text { Severe cervicitis } \\
\text { Discharge (total) } \\
\text { Severe discharge (total) } \\
\text { Severe discharge only } \\
\text { Severe discharge }+1 \text { other mild or severe sign } \\
\text { Any discharge }+1 \text { severe sign } \\
\text { Any discharge }+ \text { multiple signs } \\
\text { No discharge but multiple signs } \\
\text { Vaginal ulceration } \\
\text { Thrush plaques }\end{array}$ & $\begin{array}{r}280 \\
89 \\
7 \\
0 \\
24 \\
21 \\
69 \\
46 \\
74 \\
42 \\
14 \\
17 \\
31 \\
18 \\
5 \\
2 \\
2\end{array}$ & $\begin{array}{r}147 \\
61 \\
5 \\
0 \\
24 \\
21 \\
43 \\
22 \\
51 \\
35 \\
12 \\
13 \\
17 \\
16 \\
5 \\
1 \\
1\end{array}$ & $\begin{array}{r}133 \\
28 \\
2 \\
0 \\
0 \\
0 \\
26 \\
24 \\
23 \\
7 \\
2 \\
4 \\
14 \\
2 \\
0 \\
1 \\
1\end{array}$ \\
\hline
\end{tabular}


combination with other severe signs was observed most commonly (74). Severe discharge was observed in 42 women and occurred independently of other signs in 14 of them. Significantly more reports of discharge were made by clinician I than by clinician II $(P<0.001)$. Severe vaginitis, vulvitis or cervicitis, or combinations of these, rarely occurred independently of discharge. Cervicitis was the next most frequently observed sign and was severe in 46 women; mild cervicitis, occurring in combination with multiple signs of lower genital tract morbidity, was found in 69 women $(78 \%)$. Vaginitis was observed and was nearly always severe $(88 \%)$, but severe vulvitis was not observed. There were statistically significant differences in the signs of vaginitis $(\mathrm{P}<0.001)$ noted by the two clinicians. Discharge combined with multiple mild or a single severe sign was less frequently noted by clinician II.

There was no correlation between morbidity and gestational stage at the time of examination. Although women booking in the third trimester showed some increase in the incidence of minor signs, this was not statistically significant, and the overall incidence of morbidity did not vary throughout pregnancy.

The relationship between selected groups and morbidity is shown in tables VI and VII. There is a tendency for some increase in morbidity in those booking late and in grandiparous patients, but the numbers in the group are few (table VI). When a laboratory report was requested on clinical grounds ( $16 \%$ of total population), when there was a past history of vulvovaginitis ( $14 \%$ of total population), or when excess polymorphs were seen in the Gram

\begin{tabular}{|c|c|c|c|c|}
\hline \multirow[t]{2}{*}{ Lower Genital Tract } & $\begin{array}{l}\text { Total } \\
\text { Incidence }\end{array}$ & $\begin{array}{l}\text { Age } \\
>34 \mathrm{yr}\end{array}$ & $\begin{array}{l}\text { Parity } \\
>4\end{array}$ & $\begin{array}{l}\text { Gestation } \\
>25 w k\end{array}$ \\
\hline & No. $\%$ & No. \% & No. $\%$ & No. $\%$ \\
\hline $\begin{array}{l}\text { Healthy } \\
\text { Slightly morbid } \\
\text { Severely morbid }\end{array}$ & $\left.\begin{array}{c}83 \\
108 \\
89\end{array}\right\} 70$ & $\left.\begin{array}{l}4 \\
5 \\
7\end{array}\right\} 75$ & $\left.\begin{array}{l}1 \\
3 \\
1\end{array}\right\} 80$ & $\left.\begin{array}{l}3 \\
8 \\
4\end{array}\right\} 80$ \\
\hline Total & 280 & 16 & 5 & 15 \\
\hline
\end{tabular}

Table VI Lower genital tract morbidity in obstetric high risk groups filmed HVS ( $28 \%$ of the total population) the numbers of patients with morbidity of the lower genital tract was increased compared with the rest of the population (table VII). This was statistically significant in cases where a laboratory report was requested $(P<0.001)$ and when there was a past history of vulvovaginitis $(P<0.05)$.

Ninety-three percent of smears stained by Papanicolaou's method showed grade I cytology, 7\% showed grade II, and one patient had a grade III cervical smear.

Sixty-six percent of those with morbidity had fewer than one polymorphonuclear leucocyte per high-power field in the Gram-stained film. The presence of excess polymorphonuclear leucocytes ( $>1 / \mathrm{HPF}$ ) proved a useful index of morbidity since only 10 of 77 such women had a healthy lower genital tract: this is statistically significant $(P<$ 0.001 ). Slight discharge, alone or in combination with a reddened cervix, was commonly noted, and significantly more women with excess polymorphonuclear leucocytes $(61 \%)$ had cervicitis than any other sign of lower genital tract morbidity $(\mathrm{P}<0.01)$.

\section{Discussion}

So far as we can assess, the population studied was in no way deviant from that expected for a hospital in South-East England, and it was comparable with a group studied previously in the same hospital (Carroll et al, 1973). Distinctions relating to social class were not made since those based on occupation can be highly misleading; nor did we attempt to enquire into sexual habits or personal hygiene. A majority of patients were Caucasian aged between 18 and 34, who booked between the 13th and 25th week of pregnancy. None had diabetes, none was on steroid therapy, and only $2 \%$ had haemoglobin levels lower than $11 \mathrm{~g} / \mathrm{dl}$. Six percent had significant bacteriuria. Three percent of the population had received antimicrobial therapy in the recent past. Of other conditions, haemorrhoids were the most frequently encountered, occurring in $4 \%$ of those studied.

The most common complaints were of discharge $(42 \%)$, irritation $(15 \%)$, or both $(11 \%)$, and $14 \%$

\begin{tabular}{|c|c|c|c|c|c|c|c|c|}
\hline \multirow[t]{2}{*}{ Lower Genital Tract } & \multicolumn{2}{|c|}{ Total Incidence } & \multicolumn{2}{|c|}{$\begin{array}{l}\text { Laboratory Report } \\
\text { requested }\end{array}$} & \multicolumn{2}{|c|}{$\begin{array}{l}\text { Past History of } \\
\text { Vulvovaginitis }\end{array}$} & \multicolumn{2}{|c|}{$\begin{array}{l}\text { Excess Polymorphs } \\
\text { in Gram Film }\end{array}$} \\
\hline & No. & $\%$ & No. & $\%$ & No. & $\%$ & No. & $\%$ \\
\hline $\begin{array}{l}\text { Healthy } \\
\text { Slightly morbid } \\
\text { Severely morbid }\end{array}$ & $\left.\begin{array}{c}83 \\
108 \\
89\end{array}\right\}$ & $\begin{array}{l}30 \\
70\end{array}$ & $\left.\begin{array}{c}4 \\
8 \\
33\end{array}\right\}$ & $\begin{array}{r}9 \\
91\end{array}$ & $\left.\begin{array}{c}6 \\
16 \\
18\end{array}\right\}$ & $\begin{array}{l}15 \\
85\end{array}$ & $\left.\begin{array}{l}10 \\
37 \\
30\end{array}\right\}$ & $\begin{array}{l}13 \\
87\end{array}$ \\
\hline Total & 280 & & 45 & & 40 & & 77 & \\
\hline
\end{tabular}

Table VII Lower genital tract morbidity in other high risk groups 
of patients admitted a past history of vulvovaginitis. This high figure illustrates the frequency of the disease in the general population and emphasizes the need for further studies on its pathogenesis, prophylaxis, and treatment. The study confirmed the notorious discrepancy between complaint of discharge and its objective assessment by trained observers. No discharge was observed in $17 \%$ of those who complained of it, but it was observed in $32 \%$ of those who did not. There was, however, a remarkable degree of variation between the two clinical observers with respect to the complaint and the demonstration of discharge $(P<0.001)$, suggesting that clinical criteria are by no means so uniform as was supposed.

Most patients with severe morbidity had heavy discharge, alone or in combination with other signs $(74 / 89-83 \%)$, but cervicitis was also very common $(69 / 89-78 \%)$, as was vaginitis $(24 / 89-27 \%)$. Vaginal ulceration and thrush plaques were the least frequently observed signs $(2 / 89-2 \%)$. There was a tendency for greater morbidity in women booking after the 25th week of pregnancy and in grand multiparae, but the numbers in these groups were too few to signify.

There was a statistically significantly increased frequency of morbidity in women for whom a laboratory report was requested $(P<0.001)$, which, despite the variation in observations recorded, must reflect a high degree of clinical acumen. The requests included four on women with no past history of vulvovaginitis whose lower genital tracts were reported as apparently healthy. Morbidity was also increased significantly $(P<0.01)$ in those with a past history of vulvovaginitis, which may be indicative of inadequate treatment of the condition. The presence of polymorphonuclear leucocytes in excess of 1 per high-power field, correlated with morbidity, notably cervicitis $(P<0.001)$. This association was suggested by Carroll et al (1973).
We believe that ours is the most detailed clinicah study of the lowergenital tract recorded in pregnancy. Although certain diseases, such as candidosis andgenital herpes, have been described in great detai in both pregnant and non-pregnant women (sees Hurley et al, 1974; Winner and Hurley, 1964응 Poste et al, 1972), we find no account, other than that of Carroll et al (1973), of systematic observa-त्ळ tions on large groups of unselected pregnanto women. We believe that such studies are basic to ${ }^{\text {क }}$ the evaluation of the rôle of microbes, other than $\overrightarrow{0}$ the accepted pathogens, in the causation of vaginitis, $\overrightarrow{-}$ vulvovaginitis, and cervicitis for, apart from response to specific therapy, any postulated causal relation ship must be based on clinicopathological correlation.

We are grateful to the nursing staff of the antenatab clinics, and to Dr G. King and Dr D. Johnstone,? who helped to program the data.

\section{References}

Carroll, C. J., Hurley, Rosalinde, and Stanley, Valerie $C_{\mathbb{D}}$ (1973). Criteria for diagnosis of Candida vulvovaginitis. J. Obstet. Gynaec. Brit. Cmwlth, 80, 258-263.

de Louvois, J., Stanley, Valerie C., and Hurley, Rosalingle (1975). Microbial flora of the lower genital tract dureng pregnancy: relationship to morbidity. J. clin. Path., 731-735.

Hurley, R., Stanley, V. C., Leask, B. G. S., and de Louvois J. (1974). Microflora of the vagina during pregnancy. In The Normal Microbial Flora of Man, p. 155. Academico

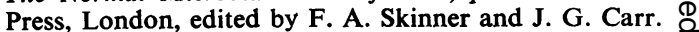
Hutfield, D. C. (1970). Herpes genitalis as a venereal disease Brit. J. Hosp. Med., 3, 881-884.

Jeffcoate, T. N. A. (1967). Principles of Gynaecology, 3rdP edition. Butterworths, London.

Poste, G., Hawkins, D. F., and Thomlinson, J. (1972)? Herpesvirus hominis infection of the female genital tract Obstet. and Gynec., 40, 871-890.

Winner, H. I. and Hurley, Rosalinde. (1964). Candid albicans. J. \& A. Churchill, London. 